九州大学学術情報リポジトリ

Kyushu University Institutional Repository

\title{
Unsteady-State Heat Transfer between Solid Particles and Gas in Fluidized Bed
}

Murata, Satoshi

Laboratory of Agricultural Process Engineering, Faculty of Agriculture, Kyushu University

https://doi.org/10.5109/23769

出版情報：九州大学大学院農学研究院紀要. 27 (3/4)，pp. 159-163，1983-02. Kyushu University バージョン：

権利関係 : 


\title{
Unsteady-State Heat Transfer between Solid Particles and Gas in Fluidized Bed
}

\author{
Satoshi Murata \\ Laboratory of Agricultural Process Engineering, Faculty of \\ Agriculture, Kyushu University 46-05, \\ Fukuoka 812 \\ (Received October 6, 1982)
}

\begin{abstract}
The unsteady-state heat transfer equations which include the plug and backmix flow in particular cases are derived, and the analytical solutions are obtained under the conditions of initial uniform temperature of solid particles and constant inlet gas temperature. Furthermore these results are extended to the case of the temperature gradient existing within the solid particles.
\end{abstract}

\section{INTRODUCTION}

The unsteady-state heat transfer between particles and gas in fluidized bed is concerned with heating, cooling and drying products. In this paper general equations containing plug and backmix flow are shown and these results are extended to the case of the temperature gradient existing within the spherical particles.

\section{THE BASIC EQUATIONS AND THEIR SOLUTIONS}

\section{Assumptions}

1) The thermal properties of the gas and solid particles are independent of temperature.

2) The temperature gradient within the particles is negligible compared with surface-film gradient. Due to sufficient mixing of particles, it can be assumed that at any given time the temperature of the solid is uniform throughout the bed.

3) Heat losses are negligible.

4) The rate of heat transfer from gas to solid at any point is proportional to the average difference in temperature between gas and solid at that point.

5) Mass mixing of gas in the flow direction conducts the heat in the same manner as ordinary conduction. Therefore total heat conductivity can be derived from these two heat conduction methods.

These assumptions 1 to 4 have also been suggested by Warmsley and Johanson (1954). In the majority of fixed bed the heat energy transport by the conduction are negligible compared with the enthalpy transport. However in 
fluidized bed the mixing of gas caused by fast forward and backward movement of particles is so violent that the heat transportation by mixing cannot be neglected except in plug flow.

Basic equations

Taking a differential height of bed $\mathrm{dx}$, a heat balance at any time $\boldsymbol{\theta}$ gives

$\left(\begin{array}{l}\text { heat input by enthalpy } \\ \text { and conduction of gas }\end{array}\right)-\left(\begin{array}{l}\text { heat output by enthalpy } \\ \text { and conduction of gas }\end{array}\right)$

$$
\begin{array}{r}
=\left(\begin{array}{l}
\text { heat transferred } \\
\text { to solid }
\end{array}\right)+\left(\begin{array}{l}
\text { heat accumulation } \\
\text { by gas }
\end{array}\right), \\
k_{g} \frac{\partial^{2} t_{g}}{\partial x^{2}}-\left(C_{p g} G\right) \frac{\partial t_{g}}{\partial x}=a h\left(t_{g}-t_{s}\right)+\left(\rho_{g} C_{p g} f\right) \frac{\partial t_{g}}{\partial \theta} .
\end{array}
$$

Neglecting heat accumulation by gas in the same manner as suggested by Warmsley and Johanson (1954) and Donnadieu (1961), Eq. (1) is reduced to

$$
\left[\frac{\partial^{2}}{\partial x^{2}}-\left(\frac{C_{p g} G}{k_{g}}\right) \frac{\partial}{\partial x}-\left(\frac{a h}{k_{g}}\right)\right]\left(t_{g}-t_{s}\right)=0 \text {. }
$$

The heat accumulated by overall solids of the bed balances to the heat transferred at every point in the bed. This gives

$$
C_{p s} W \frac{\partial t_{s}}{\partial \theta}=S a h \int_{0}^{L}\left(t_{s}-t_{s}\right) \mathrm{d} x .
$$

Eq. (2) and Eq. (3) are the basic equations of this problem.

\section{Initial condition}

$$
t_{s}=t_{s 0}, \quad \mathrm{e}=0 \text {. }
$$

\section{Boundary conditions}

Converting rational boundary conditions derived by Yagi and Miyauchi (1953) on the analysis of the residence time curve of the reactor into the heat transfer of this problem, the following equations are obtained.

B.C. I

$$
\frac{\partial}{\partial x}\left(t_{z}-t_{s}\right)=\left(\frac{C_{p \varepsilon} G}{k_{g}}\right)\left(t_{g}-t_{s i}\right), \quad x=0,
$$

B.C. II

$$
\frac{\partial}{\partial x}\left(t_{z}-t_{z i}\right)=0, x=L .
$$

\section{Solutions}

$$
\begin{aligned}
t_{s}-t_{g t} & =\left(t_{s 0}-t_{g i}\right) e^{-E \theta} \\
t_{g}-t_{g i} & =\left(t_{s 0}-t_{g i}\right)(1-\Phi(x)) e^{-E \theta} \\
& =\left(t_{g}-t_{g i}\right)_{0} e^{-E \theta}
\end{aligned}
$$

where 


$$
\begin{aligned}
& \emptyset(x)=C_{A} e^{\alpha x}+C_{B} e^{\beta x}, \\
& C_{A}=-\frac{(\alpha+\beta) \beta e^{L \beta}}{\alpha^{2} e^{L \alpha}-\beta^{2} e^{L \beta}}, \\
& C_{B}=\frac{(\alpha+\beta) \alpha e^{L \alpha}}{\alpha^{2} e^{L a}-\beta^{2} e^{L \beta}}, \\
& E=\frac{C_{p g} w}{C_{p s} W}(1-\Phi(L)), \\
& \alpha=\left(\frac{C_{p g} G}{2 k_{g}}\right)+\sqrt{\left(\frac{C_{p g} G}{2 k_{g}}\right)^{2}+\left(\frac{a h}{k_{g}}\right),} \\
& \beta=\left(\frac{C_{p g} G}{2 k_{g}}\right)-\sqrt{\left(\frac{C_{p g} G}{2 k_{g}}\right)^{2}+\left(\frac{a h}{k_{g}}\right)} .
\end{aligned}
$$

\section{Plug flow}

The following results can be proved mathematically in the case where $k_{g}$ approaches zero.

$$
\begin{aligned}
& \lim _{k_{g} \rightarrow 0}=\infty, \\
& \lim _{k_{g} \rightarrow 0}=-\frac{h A}{C_{p g} G}, \\
& \lim _{k_{g} \rightarrow 0} E=\frac{C_{p g} w}{C_{p s} w}\left(1-e^{-\frac{h A}{C_{p g} w}}\right), \\
& \lim _{k_{g} \rightarrow 0} 0(x)=\mathrm{e}^{-\frac{h A}{C_{p g} w}} \frac{x}{L} .
\end{aligned}
$$

These results agree with Donnadiew's results.

\section{Backmix flow}

The following results can also be proved.

$$
\begin{aligned}
& \lim _{k_{\boldsymbol{g}} \rightarrow \infty} \alpha=\lim _{k_{\boldsymbol{g}} \rightarrow \infty} \beta=0, \\
& \lim _{\boldsymbol{k}_{\boldsymbol{g}} \rightarrow \infty} \emptyset(x)=\frac{C_{p g} w}{C_{p g} w+h A},
\end{aligned}
$$

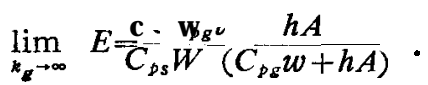

These agree with Warmsley-Johanson's results.

\section{EXTENSION TO THE CASE OF TEMPERATURE GRADIENT WITHIN SOLID PARTICLES}

Eq. (2) holds true in the case of uniform temperature of solid, and the same initial and boundary conditions. 


$$
t_{g}=(1-\emptyset(x)) t_{s}(R)+\emptyset(x) t_{g i} .
$$

Laplace transformation gives

$$
F_{g}=(1-\emptyset(x)) F_{s}(R)+\frac{1}{p} \emptyset(x) t_{g t} .
$$

In place of Eq. (3) the following equation is derived by Duhamel's theorem of heat conduction and convolution theorem of Laplace transformation (Carslaw and Jaeger, 1959).

$$
F_{s}(R)=F S(R)(\underbrace{p}_{L} \int_{0}^{L} F_{s} \mathrm{~d} x) .
$$

The solutions of Eq. (23) and Eq. (24) are derived as follows by assuming a sphere of isotropic solid particles.

$$
\frac{t_{s}(r)-t_{g i}}{t_{s 0}-t_{g i}}=2\left(R h^{\prime}\right) \sum_{n=1}^{\infty} e^{-\kappa \gamma_{n}^{2} \theta} \frac{\gamma_{n}^{2}+\left(R h^{\prime} E-1\right)^{2}}{\gamma_{n}^{2}\left(\gamma_{n}^{2}+r h^{\prime} E\left(r h^{\prime} E-1\right)\right)} \frac{\sin \gamma_{n} \sin \left(\gamma_{n}(r / R)\right)}{\gamma_{n}} \frac{\gamma_{n}(r / R)}{,},
$$

where the $\gamma_{n}$ 's are the non-zero positive roots of

$$
\gamma \cot \gamma+R h^{\prime} E-1=0 .
$$

The temperature of gas $t_{g}$ can be obtained by Eq. (22) from the temperature of the solid $t,(R)$.

\section{NOMENCLATURE}

A : Surface area of solid particles

$a$ : Surface area of solid in unit volume of bed

$C_{A}$ : Defined in Eq. (10)

$C_{B}$ : Defined by Eq. (11)

$C_{p g}:$ Specific heat of gas

$C_{p s}:$ Specific heat of solid

$E \quad$ : Defined by Eq. (12)

$F_{g}$ : Laplace transform of gas temperature

$F_{s}$ : Laplace transform of solid temperture

$F S$ : Laplace transform of solid temperature in which the initial temperature is zero, while radiation takes place into a medium at temperature unity

$f \quad$ : Void ratio

$G$ : Mass velocity

$h$ : Heat transfer coefficient

$h$ ' : Relative heat transfer coefficient

$k_{g}:$ Total heat conductivity

$L \quad$ : Bed height

$P \quad$ : Variable of Laplace transform

$R \quad$ : Radius of solid sphere

$r$ : Radial coodinate in sphere $\left[\mathrm{m}^{2}\right]$

$\left[\mathrm{m}^{2} / \mathrm{m}^{3}\right]$

$[-]$

$[-]$

$\left[\mathrm{kcal} / \mathrm{kg}^{\circ} \mathrm{C}\right]$

$\left[\mathrm{kcal} / \mathrm{kg}^{\circ} \mathrm{C}\right]$

$\left[\mathrm{hr}^{-1}\right]$

\section{r-1}

C-1

$[-]$

$[-]$

$\left[\mathrm{kg} / \mathrm{m}^{2} \mathrm{hr}\right]$

$\left[\mathrm{kcal} / \mathrm{m}^{2} \mathrm{hr}^{\circ} \mathrm{C}\right]$

$\left[\mathrm{m}^{-1}\right]$

$\left[\mathrm{kcal} / \mathrm{mhr}^{\circ} \mathrm{C}\right]$

[m]

[m]

[m]

[m] 
$S$ : Cross sectional area

$\left[\mathrm{m}^{2}\right]$

$t_{g}:$ Temperature of gas

$t_{g i}$ : Inlet temperature of gas

$t_{\mathrm{s}}$ : Temperature of solid particles

$\left[{ }^{\circ} \mathrm{C}\right]$

$t_{s 0}:$ Initial temperature of solid particles

$\left[{ }^{\circ} \mathrm{C}\right]$

$W$ : Weight of solid particles

$[\mathrm{kg}]$

$w$ : Mass flow rate of gas

$x$ : Coordinate

Greek

$\alpha \quad$ Defined by Eq. (13)

$\beta \quad$ : Defined by Eq. (14)

$\gamma \quad$ Defined by Eq. (26)

$\theta \quad:$ Time

$\kappa \quad$ : Thermal diffusivity of solid

[hr]

$\rho_{g} \quad$ : Specific weight of gas

$\emptyset(x)$ : Defined by Eq. (9)

\section{REFERENCES}

Carslaw, H. S. and J. C. Jaeger 1959 Conduction of Heat in Solid. Oxford Univ: Press (England), pp. 30-33

Donnadieu, G. 1961 Transmission de la chaleur dans les milieux granulaires-Etude de lit fix et du lit fluidise--. Rev. Inst. Fr. du Petrole, 16: 1330-1356

Warmsley, W. W. and L. N. Johanson 1954 Fluidized bed heat transfer. Chem. Eng. Prog., 50: $347-355$

Yagi, S. and T. Miyauchi 1953 On the residence time curves of the continuous reactor: Kagaku-Kogaku (Chem.Eng. Japan), 17: 382-386 